\title{
Hinter den Kulissen der Welt, ewige Ruhe?
}

Hedi Meierhans

Korrespondenz:

Dr. med. Hedi Meierhans Solenberg 38

CH-8723 Maseltrangen

he.meierhans[at]bluewin.ch
«Herr, gib ihm die ewige Ruhe und das ewige Licht leuchte ihm», tönte es an der Beerdigung meines Vaters. Ich konnte mir darunter als 10-Jährige nichts vorstellen. Auch später hörte ich das regelmässig in der Kirche, und regelmässig kam es am andern Ohr wieder heraus.

Erst nach meinem spontanen Licht-Liebe-Erlebnis mit ca. 25 Jahren erhielt ich eine Ahnung, was Licht und Liebe ist, totaliter aliter, d.h., ich hatte keine Vorstellung vorher. Da ich aber mitten im Studium war, beschäftigte ich mich vor allem mit Naturwissenschaften. Sobald ich jedoch damit fertig war fürs erste, befasste ich mich mit Philosophie,

\section{«Ich habe in diesem Buch mit allen} Tabus gebrochen.»

Daseinsanalyse und Anthroposophie. Die Fragen: «Wer bin ich, woher komm ich, wohin geht es» holten mich ein. Aber erst mit ca. 40 Jahren las ich das entscheidende Buch von Helen Greaves: «Das Zeugnis des Lichts». Nach anfänglichem Widerstand wurde dieses Buch zum faszinierenden Anstoss weiterzuforschen und mich mit Nahtoderfahrungen zu beschäftigen, hörte ich doch von Patienten Erstaunliches. Das Thema wurde in Medizinerkreisen aber meist belächelt oder abgewehrt, bis ich «zufällig»auf Pim van Lommel, holländischer Kardiologe und Nahtodforscher, stiess.

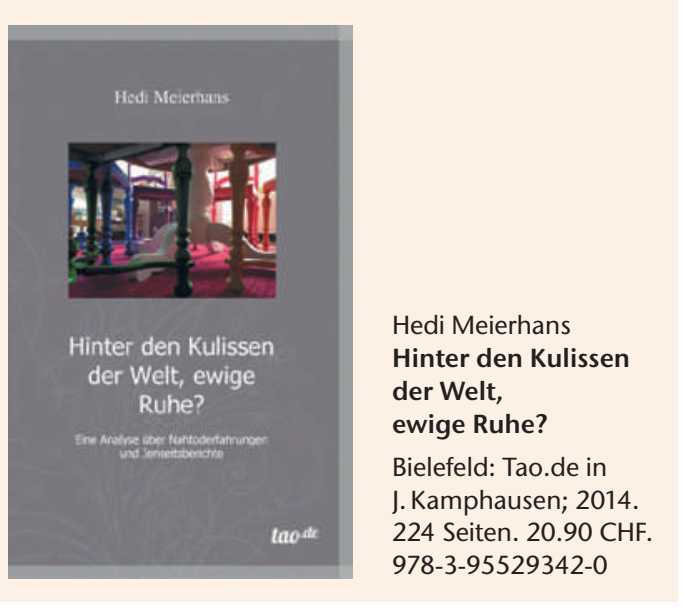

Jetzt wollte ich es wissen. Ich recherchierte auf allen Seiten und bin jetzt auf dem aktuellen Wissensstand. Ich kam zum Schluss, dass eigentlich alles Wissen für einen Paradigmenwechsel schon da wäre, aber es weder in die Wissenschaft noch in den gesellschaftlichen Alltag integriert ist. Ich stellte auch fest,

\section{«Vor der Wahrheit braucht man sich nicht zu fürchten, sie hilft einem immer weiter.»}

dass in unseren Kliniken das Thema Nahtod fast unbekannt ist. So kam ich auf die Idee, ein Büchlein für das Gesundheitspersonal zu schreiben. Dann sah ich, dass es für viele Menschen interessant ist, da dieses Thema früher oder später aktuell wird und die Erkenntnisse, die man daraus ziehen kann, vor allem für das Leben im Jetzt wichtig sind. Damit habe ich mir auch mein eigenes kleines Lehrbuch geschrieben, das mich wieder zentriert, wenn ich mal am Abdriften bin. Da ich aber als Psychiaterin von der geisteswissenschaftlichen Seite her komme, interessierte mich vor allem der Inhalt der Nahtoderfahrungen und der Vergleich zu den Jenseitsberichten, und was man daraus für Konsequenzen ziehen kann.

Auch das Thema Organtransplantation habe ich kurz gestreift, hatte ich doch eine durch eine Transplantation traumatisierte Patientin mit einer Nahtoderfahrung (NTE) zu behandeln. Um es vorweg zu nehmen: Ich bin nicht gegen Transplantationen, aber für einen bewussteren Umgang damit, das heisst gute Information, und dafür müsste man Studien über die psychischen Veränderungen machen, die mit einer Transplantation einhergehen. Das wäre für alle Beteiligten nützlich. Vor der Wahrheit braucht man sich nicht zu fürchten, sie hilft einem immer weiter.

Durch das Studium der NTE und eigene Erfahrungen konnte ich auch die Kernaussagen der christlichen Religion neu beleuchten, insbesondere das Abendmahl, das den Menschen aktuell durch gewisse bischöfliche Aussagen sehr zu denken gibt, mit Recht.

Ich habe in diesem Buch mit allen Tabus gebrochen. Ich möchte den Leser durch ausführlich beschriebene faszinierende Berichte und deren Analyse auf die Spuren der Ewigkeit hinter die Kulissen der Welt führen. 